\title{
ПОВОРОТ НА ВОСТОК: ИТОГИ ПЯТИ ЛЕТ
}

Аннотация. В сентябре 2013 2. в третьем номере журнала «Современная Европа» была опубликована статья "Россия между Европой и Азией», в которой анализировались вопросы «двухконтинентальности» российской политики. За эти пять лет произошло значительное ухудшение отношений между Западом и Россией, что повысило роль Востока в российской политике и экономике. «Поворот на Восток» ставит перед Россией как задачи развития наших отношений со странами Азии, так и решения сочииально-экономических проблем российского Дальнего Востока.

Ключевые слова: Россия, Дальний Восток, ЕС, Китай, торговля.

Россия является не только крупнейшей по территории европейской страной, располагаясь на $37 \%$ континента, но и крупнейшей азиатской страной, занимая почти треть её площади. Являясь по своему этническому составу страной европейской - более $80 \%$ населения России составляют славяне - Россия по праву позиционирует себя страной, прежде всего европейской. Однако её история и география создали предпосылки для постоянного поиска выбора между цивилизационной принадлежности к Европе и склонностью к стереотипам нашего азиатского прошлого ${ }^{1}$. Политический, а до определённой степени и экономический, выбор между Европой и Азией особо актуализировался после событий 2014 г. в Украине, когда отношения с Западом приняли форму конфронтации.

Официально российский «поворот на Восток» мотивировался необходимостью воспользоваться опережающим развитием экономики стран Тихоокеанского региона, о чём президент РФ В.В. Путин неоднократно говорил в своих выступлениях ${ }^{2}$. Однако успехи азиатской экономики были не единственной причиной активизации восточного вектора российской политики. Активный поиск союзников в Азии, и в первую очередь, попытки расширить и укрепить стратегическое партнёрство с Китаем, были продиктованы не только стремлением проводить естественную для евро-азиатской страны многовекторную политику. Постукраинский кризис отношений России с Западом, очевидно, стимулировал интерес, как к политике в отношении соседей на Востоке, так и к нашему Дальнему Востоку.

За эти пять лет были предприняты усилия для укрепления позиций России на азиатском направлении. С 2014 по 2018 гг. состоялось более 20 встреч между руководством России и Китая, 25 встреч между президентом В.В. Путиным и премьером Японии Синдзо Абэ; между Россией и Китаем был подписан ряд важных экономических контрактов. В 2015 г. был создан Евразийский Экономический Союз (ЕАЭС), куда кроме России вошли Белоруссия, Казахстан, Армения и Киргизия.

(C) Носов Михаил Григорьевич - член-корреспондент РАН, главный научный сотрудник, член Дирекции ИЕ РАН. Adpec: 125009, Россия, Москва, ул. Моховая, д. 11, стр. 3. E-mail: mikhailnosov@ mail.ru.

DOI: http://dx.doi.org/10.15211/vestnikieran22019612

${ }^{1}$ Подробно анализ российской «двухконтинентальности» см.: М.Г. Носов. Россия между Европой и Азией. Современная Европа. №3, 2013. С. 22-40.

${ }^{2}$ См., например: пресс-конференция президента В.В. Путина 18.12.2014. 
Во внутренней политике правительство приняло ряд важнейших решений, направленных на социально-экономическое развитие региона Дальнего Востока и Забайкалья ${ }^{1}$. По словам президента В.В. Путина «подъём Дальнего Востока - это наш национальный приоритет на весь XXI век». В мае 2017 г. Россия официально присоединилась к глобальному китайскому проекту «Один пояс, один путь» предусматривающему создание сухопутного и морского пути между Китаем и Европой и широкое развитие инфраструктуры на протяжении всей транспортной структуры. По замыслу проектировщиков часть транспортной артерии должна пройти по территории Казахстана и России, что, с российской точки зрения, укрепит развитие отношений России со странами Центральной Азии.

\section{Экономические итоги восточной политики России}

В 2019 г. можно подвести предварительные итоги «нашего движения на Восток», происходящего в сложных условиях санкционной политики Запада. Динамика и распределение внешней торговли России за пять лет представлена в таблице 1.

Таблица 1

Динамика внешней торговли России 2013-2018 гz. (в млрд долл. США)

\begin{tabular}{|l|c|c|c|c|c|c|c|c|}
\hline & \multicolumn{4}{|c|}{ Импорт } & \multicolumn{4}{c|}{ Экспорт } \\
\hline & 2013 & $\%$ & 2018 & $\%$ & 2013 & $\%$ & 2018 & $\%$ \\
\hline Мир & 314,9 & 100 & 238,1 & 100 & 527,3 & 100 & 449,3 & 100 \\
\hline Европа & 170,7 & 54,2 & 112,1 & 47,1 & 284,8 & 54,0 & 245,0 & 54,5 \\
\hline ЕС & 134,1 & 42,6 & 89,3 & 37,5 & 241,3 & 45,8 & 205,1 & 45,6 \\
\hline Нидерланды & 5,8 & 1,9 & 3,7 & 1.8 & 69,3 & 13,1 & 43,5 & 9,7 \\
\hline Германия & 37,9 & 12,0 & 25,5 & 10,7 & 23,0 & 4,4 & 34,1 & 7,6 \\
\hline Италия & 14,6 & 4,6 & 10,6 & 4,4 & 29,2 & 5,5 & 16,4 & 3,7 \\
\hline Франция & 13,0 & 4,1 & 9,6 & 4,0 & 5,9 & 1,1 & 7,8 & 1,7 \\
\hline Другие страны ЕС & 71,3 & 22,6 & 49,4 & 19,1 & 127,4 & 24,2 & 101,8 & 22,7 \\
\hline Азия & 11,0 & 35,3 & 100,5 & 42,2 & 146,4 & 28,0 & 165,3 & 36,8 \\
\hline Китай & 53,2 & 16,9 & 52,2 & 21,9 & 35,6 & 6,8 & 56,0 & 12,5 \\
\hline Япония & 13,6 & 4,3 & 8,8 & 3,7 & 19,7 & 3,7 & 12,4 & 2,8 \\
\hline Южная Корея & 10,3 & 3,3 & 7,0 & 2,9 & 14,9 & 2,8 & 17,8 & 4,0 \\
\hline Центральная Азия & 7,2 & 2,3 & 6,8 & 2,9 & 24,2 & 4,6 & 19,0 & 4,2 \\
\hline Казахстан & 5,7 & 1,8 & 5,3 & 2,2 & 17,2 & 3,3 & 12,9 & 2,9 \\
\hline
\end{tabular}

Источник: UNCOMTRADE, Федеральная таможенная служба России.

С 2013 по 2018 гг. российский экспорт сократился на 17,3\%, а импорт упал на 32,2\%, тогда как экспорт в ЕС уменьшился на 17,6\%, а импорт на 50,2\%, в основном за счёт сокращения импорта продукции машиностроения с 59,4 млрд долл. США до 37,3 млрд долл. Сокращение торговли было связано не только с западными санкциями, но и со снижением роста экономики России. Импорт из Белоруссии сократился с 14 млрд долл. до 12,2 млрд долл., импорт из Казахстана с 5,7 млрд долл. до 5,3 млрд долл., импорт из Республики Кореи с 10,3 млрд долл. до 7 млрд долл., импорт из Турции с 7,2 млрд долл. до 4,2 млрд.

ЕАЭС, объединяющий 183,4 млн человек, с площадью более 20 млн км ${ }^{2}$, пока ещё не играет существенной роли в российской экономике и торговле. С экономической точки зрения его потенциал составляет чуть больше 3\% мирового ВНП (по ррр) и столько же приходится на ЕАЭС в объёме мировой торговли. В торговле со странами региона Центральной Азии, которые Россия всегда считала зоной своего экономического влияния, лидерство перешло к Китаю и ЕС. В 2017 г. объём торговли Китая с регионом составил 35,9 млрд долл., торговля региона с ЕС 29,5 млрд, тогда как объём российской торговли был 22,9 млрд долл. Импорт Китая из региона составил 14,6 млрд долл., из которых 6,6 млрд долл. пришлось на импорт

\footnotetext{
${ }^{1}$ В этот регион входят области Дальневосточного Федерального Округа и два субъекта Восточно-Сибирского Федерального округа - Бурятия и Забайкальский край, присоединённые к ДВФО в 2018 г.
}

Научно-аналитический вестник ИЕ РАН, 2019, №2 
газа из Туркмении ${ }^{1}$. Готовность России участвовать в проекте «Один пояс, один путь» далеко неоднозначна. С одной стороны, Китай рассматривается как надёжный противовес российским потерям на западном направлении российской внешней политики. С другой, возможности Китая по укреплению своих экономических и политических возможностей в Центральной Азии, ставшей после создания Евразийского экономического союза важнейшим направлением российской политики, намного превосходят ресурсы Москвы. Кроме всего прочего, китайские планы по созданию транспортных коридоров Азия-Европа в будущем неизбежно станут конкурировать с транспортным потенциалом Транссиба и Северного морского пути.

Тем не менее, российское руководство неоднократно говорило, что одной из задач ЕАЭС является его сопряжение с глобальным китайским проектом «Один пояс, один путь». Одним из наиболее вероятных вариантов участия России в китайском проекте было создание общей железной дороги между Китаем и Европой. В мае 2013 г. президент В.В. Путин объявил о плане построить высокоскоростную магистраль (ВСМ) «Евразия», начав с участка Москва-Казань с её дальнейшим продлением дороги до Екатеринбурга, а затем и до Пекина. Проект ВСМ «Евразия» Москва-Пекин был официально анонсирован в январе 2015 г., а в августе 2017 г. в Министерстве транспорта РФ было представлено технико-экономическое обоснование ВСМ «Евразия» ${ }^{2}$. В конце октября 2017 г. РЖД презентовала Международному союзу железных дорог проект по строительству ВСМ «Евразия». На 19-м заседании Межправительственной комиссии по сотрудничеству между Россией и Казахстаном был согласован маршрут дороги Москва - Алтынколь на границе Казахстана и Китая. Проект был поддержан правительством России. Длина маршрута Пекин-Берлин 9447 км, из которых по территории России пройдёт 2400 км. Однако в реальности мы, к сожалению, не пошли дальше заявлений о будущем участии в развитии сотрудничества в этом проекте. Планируемая длина магистрали несколько раз сокращалась, и последним вариантом ВСМ стала дорога МоскваКазань, ввод которой был намечен на январь 2023 г. Однако строительство дороги так и не началось, а в декабре 2018 г. министр финансов РФ А. Силуанов заявил, что «экономическая целесообразность строительства ВСМ Москва-Казань фактически отсутствует» ${ }^{3}$.

Одним из крупнейших «азиатских» проектов России стало строительство газопровода «Сила Сибири», проложенного от Чаядинского месторождения в Республике Саха и Ковыктинского месторождения в Иркутской области до Владивостока вдоль границы с Китаем. Проект, который финансируется совместно Газпромом и китайской компанией CNPC предусматривает ежегодную поставку 38 млрд м ${ }^{3}$ российского газа в Китай в течение 30 лет в соответствии с подписанным в 2014 г. российско-китайским контрактом. Стоимость контракта составляет 400 млрд долл., из которых предоплата китайской компании CNPC составила 25 млрд долл. ${ }^{4}$ Поставки газа в Китай должны начаться в декабре 2019 г. В дополнение к поставкам через «Силу Сибири» планируется так называемый Западный коридор или «Сила Сибири-2» по маршруту Ямал-Китай через Алтай в Синьцзян с мощностью в 30 млрд м ${ }^{3}$ о чём было достигнуто предварительное соглашение в 2014 г.

Ввод в строй «Силы Сибири» может кардинально изменить ситуацию с газоснабжени-

\footnotetext{
${ }^{1}$ UN COMTRADE. URL: https://trademap.org (дата обращения: 30.04.2019).

${ }^{2}$ Со скоростью сметы. Коммерсанть. 24.08.2017. URL: https://www.kommersant.ru/doc/3391523 (дата обращения: 30.04.2019).

${ }^{3}$ Силуанов счёл проект BCM Москва-Казань экономически нецелесообразным. Известия. 25.12.2018. URL: https://iz.ru/827581/2018-12-25/siluanov-schel-proekt-vsm-moskva-kazan-ekonomicheskii-netcelesoobraznym (дата обращения: 30.04.2019).

${ }^{4}$ Россия сегодня. Прайм Агентство Экономической Информации (1 prime.ru 21.05.2014).
}

Научно-аналитический вестник ИЕ РАН, 2019, №2 
ем Дальнего Востока, что будет способствовать развитию региона. Вопрос о рентабельности поставок газа в Китай не вызывает никаких сомнений у главы «Газпрома» А. Миллера. В феврале 2019 г. он сказал, что «формула цены, которая прописана в контракте с Китаем, позволяет нам при нынешних ценах на углеводороды чувствовать себя абсолютно уверенно» ${ }^{1}$. Однако, поскольку Миллер сказал о «нынешних ценах», а цены на газ привязаны к ценам на нефть, не совсем ясно, как будет окупаться проект в случае возможного падения цен на нефть.

\section{Дальний Восток}

В рамках «движение на Восток» получила дальнейшую разработку национальная программа развития российского Дальнего Востока. В 2013 г. на заседании Правительственной комиссии по вопросам социально-экономического развития Дальнего Востока в октябре 2013 г. в Комсомольске-на-Амуре премьер-министр Д.А. Медведев, оценивая итоги существовавших программ по развитию региона, отметил, что «все подходы, все модели, которые мы использовали в последние годы для того, чтобы кардинальным образом изменить развитие Дальнего Востока, не являются абсолютно удачными. Они не принесли пока того результата, на который мы рассчитывали. Они не дали экономического эффекта»².

На этом же заседании, по предложению премьера, было принято решение о создании на Дальнем Востоке «территорий опережающего социально-экономического развития» (ТОЭСР), которые должны были дополнить созданные в 2005 г. особые экономические зоны (ОЭЗ) и зоны территориального развития (ЗТР), учреждённые в 2011 г. В рамках планов дальнейшего развития региона в 2015 г. было принято решение «О свободном порте Владивосток» (СПВ), a с 1 июня 2016 г. начал работать закон «О дальневосточном гектаре», согласно которому любой гражданин России мог бесплатно получить гектар земли.

Под эгидой Министерства по развитию Дальнего Востока были созданы Фонд развития Дальнего Востока, Фонд развития высоких технологий Дальнего Востока, Агентство Дальнего Востока по привлечению инвестиций и поддержке экспорта, Агентство по развитию человеческого капитала на Дальнем Востоке, Корпорация развития Дальнего Востока, налажен выпуск двух журналов «Экономика Дальнего Востока» и «Корпорация развития Дальнего Востока». К 1 июню 2019 г. должен быть готов проект национальной программы развития Дальнего Востока. Для этого созданы рабочие группы как на федеральном, так и на национальном уровнях. Программа развития региона на период до 2025 г. и на перспективу до 2035 г. должна быть представлена на Восточном экономическом форуме в сентябре 2019 г. В декабре 2018 г. президент РФ В.В. Путин одобрил перенос столицы ФО Дальний Восток из Хабаровска во Владивосток.

Сегодня регион Дальнего Востока является крупнейшим субъектом Российской Федерации. После присоединения к региону Бурятии и Забайкальского края на него приходится 40,6\% территории России. Хотя площадь региона в два раза больше территории Индии там на 1 января 2019 г. проживало всего 8,2 млн чел. или 5,6\% населения России. В регионе сосредоточено $100 \%$ запасов российского олова, $98 \%$ алмазов, $67,5 \%$ золота, $65 \%$ выловленной рыбы. В то же самое время регион остаётся дотационным. Из 10 субъектов Дальнего Востока лишь Сахалин является регионом-донором. Самые большие дотации из федерального бюджета получают Республика Саха и Камчатка ${ }^{3}$. Пока регион не играет большой роли ни в про-

\footnotetext{
${ }^{1}$ Миллер: «Газпром» не сомневается в рентабельности поставок газа в Китай по «Силе Сибири». URL: https:// tass.ru/ekonomika/4968313 (дата обращения: 30.04.2019).

2 Правительственная комиссия по вопросам социально-экономического развития Дальнего Востока, 24.10.2013. URL: http://government.ru/department/331/events/ (дата обращния: 30.04.2019).

${ }^{3}$ Камчатка и Саха Якутия занимают второе и третье место после Дагестана по объёму дотаций. В бюджете Кам-
} Научно-аналитический вестник ИЕ РАН, 2019, №2 
мышленности и в сельском хозяйстве России, ни во внешней торговле. На Дальний Восток в 2017 г. пришлось 6,1\% валового регионального продукта, 6,5\% экспорта и 3,1\%.

Возможность развития Дальнего Востока ограничена несколькими факторами. Прежде всего, это демографические проблемы. С 1991 по 2018 г. население Дальнего Востока сократилось с 8063 до 6 165,3 тыс. человек². С 2010 по 2018 гг. количество занятых на Дальнем Востоке сократилось с 3437 до 3 189,7 тыс. человек. В 2017 г. население России выросло по сравнению с предыдущим годом с 146,8 до 146,9 млн чел., что обеспечивалось за счёт миграции, поскольку коэффициент рождаемости составил 11,5, а коэффициент смертности 12,4 на тысячу человек. На Дальнем Востоке оба коэффициента составляют 12,1 человека на тысячу, однако регион ежегодно покидает 28 чел. на каждые 10 тыс. человек населения. В 2017 г. население Дальнего Востока сократилось по сравнению с предыдущим годом с 6183 тыс. до 6165 тыс. человек ${ }^{3}$.

Реализация программы «Дальневосточный гектар» не привела к сколь либо серьёзному притоку населения, поскольку не были предусмотрены ни финансовая поддержка программы, ни создание дорог и инфраструктуры на предлагаемых участках. В основном программой воспользовались жители самого Дальнего Востока, рассматривавшие получаемую землю как приусадебный участок.

Во-вторых, негативную роль в реализации программы играет и сокращение объёмов финансирования федеральной целевой программы «Экономическое и социальное развитие Дальнего Востока и Байкальского региона», которые сократились с 49,5 млрд рублей в 2014 г. до 32,5 млрд в 2017 г. ${ }^{4}$

Третьей проблемой является географическое положение региона. Предлагаемые правительством налоговые льготы для возможных инвесторов в разного рода зоны свободной торговли могут работать только при условии гарантий выхода на внутренние или внешние рынки. Однако возможности регионального рынка ограничены практическим отсутствием там внутреннего рынка, так и высокой конкурентоспособностью внешнего рынка, где тон задают такие страны как Китай, Япония или Южная Корея. По данным Центрального Банка России 5 чистый приток ПИИ в Россию в 2017 г. снизился на 14,3\% и составил 27,9 млрд долл. по сравнению с 32,5 млрд долл. в 2016 г. ${ }^{6}$ Основная масса вложений пришлась на добычу полезных ископаемых и финансовый сектор. Основными инвесторами в Россию являются Багамы, Кипр, Люксембург и Сингапур. В 2012-2017 гг. в экономику Дальнего Востока поступило более 65 млрд долл., из которых 68,4\% были аккумулированы в Сахалинской области - добыча и переработка углеводородного сырья ${ }^{7}$.

Путь увеличения импорта таких сырьевых товаров как газ, рыба, лес или каменный

чатки на безвозмездные дотации в 2019 г. пришлось 66\% (kampravda.ru, 05.12.2018) в бюджете Якутии 30\% (ysia.ru 19.12.2018).

Регионы России. Социально-экономические показатели, Федеральная служба государственной статистики (Росстат), М., 2018. С. 28-34. Подсчитано с учётом Забайкальского края и Бурятии.

2 В 2018 г. население Дальнего Востока увеличилась на 2 057,3 тыс. чел. после присоединения Забайкальского края и Бурятии.

3 Регионы России. Социально-экономические показатели, Федеральная служба государственной статистики (Росстат). М., 2018. С. 47-103.

${ }^{4}$ Ионова Ю.Г. Анализ результатов государственных программ по освоению и развитию Дальнего Востока. Вестник университета (Государственный Университет Управления). №6. 2017. С. 58.

5 Приток иностранных инвестиций в РФ сократился на 14\%. Независимая газета. 24.05.2018. URL: http://www. ng.ru/economics/2018-05-24/1_7231_investicions.html (дата обращения: 30.04.2019).

6 По данным ЮНКТАД в 2017 г. ПИИ в РФ составили 25 млрд долл. См.: World Investment Report $2018-$ Investment and New Industrial Polices 06.06.2018. P.187. URL: https://unctad.org.wir.

7 Минакир П.А., Суслов Д.В. Прямые иностранные инвестиции в экономике российского Дальнего Востока. Экономические и социальные перемены: факты, тенденции, прогноз. Т. 11. №3. 2018. С. 41-56.

Научно-аналитический вестник ИЕ РАН, 2019, №2 
уголь требует огромных капиталовложений и не слишком выгоден российской экономике. Дефицит населения определяет и небольшой объём внутреннего рынка. В 2017 г. на Дальний Восток пришлось $4,4 \%$ от российского объёма розничной торговли.

Наконец, негативной проблемой является общий характер программ и отсутствие в них реальных инструментов их реализации. К сожалению, многочисленные планы по социальноэкономическому развитию были сведены к обнадёживающим формулировкам типа «необходимо достичь» или «повышение даст возможность». Как справедливо отметил академик РАН П.А. Минакир «при этом до сих пор нет ответа на простой вопрос: почему при обилии стратегий почти никаких результатов в смысле стабильных темпов роста, стабильного экономического и социального развития, повышения качества жизни так и не достигнуто» ${ }^{1}$.

Анализ пяти лет нашего движения на Восток демонстрирует все трудности и препятствия на этом пути. Хотелось бы надеяться, что принятие очередной программы по развитию Дальнего Востока на период до 2035 г., которая будет представлена на Восточном экономическом форуме в сентябре 2019 г. кардинально изменит ситуацию, однако долгий и богатый опыт реализации подобных программ особой уверенности не внушает ${ }^{2}$. Развитие региона на основе создания всё новых и новых бюрократических систем не решает его многочисленных проблем. Демографическая стабильность Дальнего Востока в советское время во многом держалась на выплате «северных» надбавок. Сегодня без финансовых стимулов и создания инфраструктуры для нормальной жизни для населения региона и таких же условий для потенциальных переселенцев решить демографические проблемы будет невозможно. Проблемы нашего Дальнего Востока неразрывно связаны с общими проблемами развития российской экономики.

В 2018 г. торговля России с Азией по объёму превысила нашу торговлю с Европой. За эти пять лет Россия сумела повысить уровень своих отношений с Китаем. С 2013 по 2018 гг. российский экспорт в Китай вырос 35,6 до 56 млрд долл. Наши отношения с Китаем рассматриваются обеими сторонами как стратегические и важные для обеих сторон. Однако столь же очевидно, что для Китая отношения стратегического союза, в подлинном смысле этого понятия, то есть возвращение к условиям советско-китайского договора о дружбе, союзе и взаимной помощи невыгодны и неприемлемы. Сегодня Китай и США находятся в острой фазе экономического конфликта. Пекин и США обвиняют друг друга «в несправедливой торговле». Однако ведя ожесточённую торговую войну, стороны не прибегают к прямым военным угрозам, сохраняя нормальные деловые отношения. Во внешней торговле Китая в 2017 г. на США пришлось 8,4\% импорта и 19\% экспорта, на Россию соответственно 2,2\% и 1,9\%, что во многом определяет сдержанность Китая в политике в отношении как США, так и России. Для Китая, чьи национальные задачи в первую очередь связаны с развитием экономики, сохранение экономических связей с США и ЕС остаётся важнейшей задачей ${ }^{3}$.

Многовекторная политика необходима и России. Восточное направление российской политики не должно противопоставляться нашим традиционным интересам на Западе. Эко-

\footnotetext{
${ }_{1}^{1}$ Минакир П.А. Стратегические развилки: есть ли выход из тупика? Пространственная Экономика. 2018. С. 11.

2 После распада СССР в сентябре 1992 г. была принята Федеральная целевая программа «Экономическое и социальное развитие Дальнего Востока и Забайкалья на период до 2013 года». В дальнейшем, в апреле 1996 г., она была трансформирована в программу развития Дальнего Востока и Забайкалья на 1996-2005 гг., которая в марте 2002 г. была продлена до 2010, затем до 2013 г., а в 2013 г. ещё до 2018 г. Планировалось инвестировать в развитие регионов около 20 млрд долларов. (ФЦП Экономическое и социальное развитие Дальнего Востока и Байкальского региона до 2018 г. URL: http://assoc.khv.gov.ru.

${ }^{3}$ Подробнее об отношениях Китая с ЕС и США: Носов М.Г. ЕС и Китай: торговля и стратегия. Современная Европа. №6, 2018.
} 
номика России, включая экспорт нефти и газа и технологическое развитие, во многом зависит от наших отношений с Европой и США. Политическое и военное противостояние с Западом, в конечном итоге, не выгодно и опасно для обеих сторон.

\section{Список литературы}

Носов М.Г. Россия между Европой и Азией. Современная Европа. №3, 2013. С. 22-40.

Регионы России. Социально-экономические показатели. Федеральная служба государственной статистики (Росстат), М., 2018.

Ионова Ю.Г. Анализ результатов государственных программ по освоению и развитию Дальнего Востока. Вестник университета (Государственный Университет Управления). №6, 2017.

Минакир П.А., Суслов Д.В. Прямые иностранные инвестиции в экономике российского Дальнего Востока. Экономические и социальные перемены: факты, тенденции, прогноз. Т. 11, №3, 2018. С. 41-56.

Минакир П.А. Стратегические развилки: есть ли выход из тупика? Пространственная Экономика.2018.

Носов М.Г. ЕС и Китай: торговля и стратегия. Современная Европа. №6, 2018. С. 5-17.

\section{References}

Nosov M.G. Rossiya mezhdu Evropoj i Aziej. Sovremennaya Evropa. №3, 2013. S. 22-40.

Regiony Rossii. Social'no-ekonomicheskie pokazateli. Federal'naya sluzhba gosudarstvennoj statistiki (Rosstat). Moskva, 2018.

Ionova Yu.G. Analiz rezul'tatov gosudarstvennyh programm po osvoeniyu i razvitiyu Dal'nego Vostoka. Vestnik universiteta (Gosudarstvennyj Universitet Upravleniya). №6, 2017.

Minakir P.A., Suslov D.V. Pryamye inostrannye investicii v ekonomike rossijskogo Dal'nego Vostoka. Ekonomicheskie i social'nye peremeny: fakty, tendencii, prognoz. T. 11, №3. S. 41-56.

Minakir P.A. Strategicheskie razvilki: est' li vyhod iz tupika? Prostranstvennaya Ekonomika. 2018.

Nosov M.G. ES i Kitaj: torgovlya i strategiya. Sovremennaya Evropa. №6, 2018. S. 5-17.

\section{Turn to the East: Results of the Five Years}

Author. Mikhail Nosov, Corresponding Member of the Russian Academy of Sciences, Member of the Executive Board of the Institute of Europe. Address: 11-3, Mokhovaya str., Moscow, Russia, 125009.E-mail: mikhailnosov@mail.ru.

Abstract. In September 2013, the article «Russia between Europe and Asia» was published in the $3^{\text {rd }}$ issue of the magazine «Contemporary Europe», which analyzed the «dual continentality» of Russian politics. During these five years there has been a significant deterioration in relations between the West and Russia, which has enhanced the role of the East in Russian politics and economics. «Turning to the East» sets Russia both the tasks of developing our relations with the countries of Asia and solving the socio-economic problems of the Russian Far East.

Key words: Russia, Far East, EU, China, trade.

DOI: http://dx.doi.org/10.15211/vestnikieran22019612 